\title{
Próteses auditivas em crianças: importância dos processos de verificação e validação***
}

\author{
Hearing aids in children: the importance of the verification and \\ validation processes
}

\author{
Mara Renata Rissatto* \\ Beatriz Cavalcanti de Albuquerque Caiuby Novaes**
}

*Fonoaudióloga. Mestre em Fonoaudiologia pela Pontifícia Universidade Católica de São Paulo. Docente Pesquisadora do Curso de Fonoaudiologia da Universidade do Estado da Bahia e da União Metropolitana de Educação e Cultura (BA). Endereço para correspondência: Av. Luís Tarquínio Pontes s/n Condomíno Vog Ville (Rua Hípica Casa 13) - Lauro de Freitas - BA - CEP 42700000 (mararenata@uol.com.br).

**Fonoaudióloga. Doutora em Audiology pela Columbia University. Docente Titular da Pontifícia Universidade Católica de São Paulo.

***Trabalho Realizado na Faculdade União Metropolitana de Educação e Cultura em Lauro Freitas (BA).

Artigo Original de Pesquisa

Artigo Submetido a Avaliação por Pares

Conflito de Interesse: não

Recebido em 12.06.2008.

Revisado em 19.11.2008; 17.02.2009.

Aceito para Publicação em 04.05.2009.

\begin{abstract}
Background: during the fitting of hearing aids in children it is important, besides using a verification protocol, to have a validation process. Aim: to describe and discuss the use of a protocol for the fitting and the verification of hearing aids in children, as well as the impact of the adjustment of the acoustic characteristics in speech perception tasks. Method: ten children aging from three to eleven years were enrolled in this study. All children presented bilateral sensorineural hearing impairment, were users of hearing aids and were followed at a public hearing health care service in Bahia. The children were submitted to the following procedures: pure tone air and bone conduction thresholds; real-ear coupler difference (RECD); verification with real-ear measurement equipment: coupler gain/output and insertion gain and to speech perception tasks: "The Six-Sound Test" (Ling, 2006) and the "Word Associations for Syllable Perception" (WASP - Koch, 1999). The programmed electro acoustic characteristics of the hearing aids were compared to the electro acoustic characteristics prescribed by the DSL [i/o] v4.1 software. The speech perception tasks were reapplied on three occasions: straight after the modification of the electro acoustic characteristics, after 30 days and 60 days. Results: for more than $50 \%$ of the tested children, the programmed electro acoustic characteristics of the hearing aids did not correspond to that suggested by the DSL [i/o] software. Adequate prescription was verified in $70 \%$ of the investigated sample; this was also confirmed by the results in the speech perception tasks $(\mathrm{p}=0.000)$. This data confirmed that the mean percentage of correct answers increased after the modification of the electro acoustic characteristics. Conclusion: the use of a protocol that verifies and validates the fitting of hearing aids in children is necessary.
\end{abstract}

Key Words: Child; Hearing; Hearing Loss; Hearing Aid; Language.

\section{Resumo}

Tema: na adaptação de aparelhos de amplificação sonora individual (AASI) em crianças é fundamental além do protocolo de verificação um processo de validação. Objetivo: caracterizar um protocolo de verificação da adaptação do AASI em crianças e o impacto da adequação das características acústicas em tarefas de percepção de fala. Método: dez crianças (três a onze anos de idade) usuárias de AASI, atendidas numa unidade de atenção à saúde auditiva da Bahia, foram submetidas a: audiometria; verificação das características eletroacústicas programadas nos seus respectivos AASI por meio da medida derivada da resposta real (utilizando acoplador de $2 \mathrm{cc}$ ) e procedimentos de percepção de fala: detecção dos sons do Ling (2006) e protocolo de avaliação Word Associations for Syllabe Perception (WASP), proposto por Koch (1999). As características eletroacústicas programadas nos AASI foram comparadas com as características eletroacústicas prescritas pelo software DSL[i/o]-v4.1, e os procedimentos de percepção de fala foram reaplicados em três ocasiões: logo após as modificações das características eletroacústicas, após trinta dias e, finalmente, após sessenta dias. Resultados: em mais de $50 \%$ das crianças avaliadas as características eletroacústicas programadas nos AASI não corresponderam ao sugerido pelo software DSL[i/o], após a alteração de acordo com o software DSL[i/o], foi possível verificar a adequação da prescrição em $70 \%$ dos casos, o que também foi confirmado nos procedimentos de percepção de fala (p $=0,000)$. Este dado indicou que as porcentagens médias de acertos melhoraram após as modificações das características eletroacústicas. Conclusão: é necessária a utilização de um protocolo de verificação e validação na adaptação do AASI em crianças.

Palavras-Chave: Criança; Audição; Perda Auditiva; Auxiliares de Audição; Linguagem.

Referenciar este material como:

$\Omega$ Rissatto MR, Novaes BCAC. Hearing aids in children: the importance of the verification and validation processes (original title: Próteses auditivas em crianças: $\sum 3$ importância dos processos de verificação e validação). Pró-Fono Revista de Atualização Científica. 2009 abr-jun;21(2):131-6. 


\section{Introduction}

Children provide few and uncertain information about the performance of their individual hearing aids. Thus, it becomes ideal the use of a protocol containing: selection of the physical (model and size) and electroacoustic (gain and output) characteristics, with the use of a specific method of target gain prescription; verification of the electroacoustic characteristics performance and validation of this amplification, examining speech perception and production of the child 1-2.

The verification can be realized through behavioral procedures and objective measures: in situ measurements (performance of hearing aids on the external ear canal), and measure derived from the actual hearing aids response (performance on the $2 \mathrm{cc}$ coupler associated to the sound pressure difference measured on the $2 \mathrm{cc}$ coupler and on the external acoustic meatus - Real-Ear Coupler Difference - RECD) 3-7.

The Speech-Language Pathology field lacks on studies that critically contribute to the hearing aid adaptation process in children, especially concerning the verification process and the use of objective measures in centers accredited by the National Policy for Hearing Health Care (GM Ordinance number 2073 from 2004) 8.

Thus, this study aims to describe and discuss the application of a verification protocol for adaptation of hearing aids in children from a hearing health service, as well as to examine the impact of amplification adequacy in speech perception tasks.

\section{Methods}

The study was conducted at the Audiology Department of the Metropolitan Unit of Social Welfare and Education Association in the city of Lauro de Freitas, BA, on the period from March to October of 2006. The study was approved by the Ethics Committee of the Pontifical Catholic University of São Paulo, (number 0042 / 2005). All parents, or responsible ones, of every participant signed the Free and Informed Consent Form.

Study participants were ten children, four boys and six girls, with ages between three years and eleven years and three months. The selection criteria were as follows: children from the mentioned center, presenting bilateral neurosensorial hearing loss (congenital or acquired at up to one year of age), with degree of hearing loss ranging from moderate to profundo9, users of binaural hearing aids, and without other deficiencies and disorders on external and middle ear. The children were subjected to several procedures, composing the following protocol:

1. First Phase: audiological evaluation composed by meatoscopy (otoscope Mini Heine 2000), immitance test for confirmation of tympanometric curve type A (immittanciometer AZ7-Interacoustic), and conventional pure tone audiometry (audiometer Audiotest 227).

2. Second Phase: selection of hearing aid electroacoustic characteristics on the DSL [i / o] software, version 4.110, with the RECD measure held in accordance to instructions of the equipment used (model Unity-Siemens) and protocol described in literature 11.

3. Third Phase: verification procedure of hearing aid performance under normal conditions, that is, in accordance with the regulation with which the child first arrived at the service: measure of hearing aid electroacoustic characteristics on the $2 \mathrm{cc}$ coupler, using speech in noise acoustic stimulus with intensity of 60dB SPL for the measure of gain, and pure tone with intensity of 90dB SPL for the measurement of maximum output (equipment Unity / Siemens).

4. Fourth Phase: procedures involving speech perception tasks aiming to validate the adjustments suggested at amplification: protocol "Word Associations for Syllable Perception (WASP)12" withy dissyllable words used daily by the child. The stimuli were presented through live-voice in acoustically treated room (average noise of $43 \mathrm{~dB}$ A), with the researcher controlling the voice at intensity between $60 \mathrm{~dB}$ and $70 \mathrm{~dB} \mathrm{~A}$, and maintaining a one meter distance from the child without providing visual clues.

After these procedures, the electroacoustic characteristics prescribed by the software DSL [i / o] version 4.1 were compared to the hearing aid programming. A $3 \mathrm{~dB}$ difference was used for the determination of similar values between the gain and output electroacoustic characteristics prescribed by the DSL [i / o] software and the values found on hearing aids. According to literature, variations on the $3 \mathrm{~dB}$ difference suggested above could indicate superamplification; differences below $3 \mathrm{~dB}$ could indicate subamplification; and differences between $+/-3 \mathrm{~dB}$ would indicate similar values between prescription and programming 13 .

The hearing aids with electroacoustic characteristics different from values prescribed by the software DSL [i / o] v4.1 were re-programmed 
aiming the highest possible approximation of prescribed characteristics, being that, once again, the verification and validation procedures were performed.

Children remained with the new hearing aid program and, after periods of 30 and 60 days, returned for further assessment: meatoscopy, impedance tests, electroacoustic characteristics performance of hearing aids in the coupler, and validation procedures, with purpose of analyzing the development of speech perception and production.

Descriptive statistical analysis of variables from the study was performed, comparing the results obtained in the first and second assessment. From the suitability of acoustic characteristics at first visit, a descriptive statistical analysis of the overall behavior of percentages of correct responses in words, consonants, vowels and traces on the course of the four assessments was conducted. The descriptive statistics mean, standard deviation, minimum, median and maximum were calculated, according to Repeated Measures Analysis of Variance test. For each response, and in order to compare the means of consecutive assessments, the Bonferroni method with a significance level of 0.05 or $5 \%(\mathrm{p}<0.05)$ was conducted.

\section{Results}

Table 1 provides results of the differences of gain measures for right and left ears (frequencies from $250 \mathrm{~Hz}$ to $4 \mathrm{kHz}$ ). Percentage of differences between the value specified by the DSL [i/o] software and the value found on the hearing aids in each ear - according to the prescription with which the child first arrived (first measure) - and after the hearing aid programming - the closest possible to the prescribed (second measure) are displayed.

It can be verified that, on the first measures, less than $50 \%$ of the ears were within the prescribed gain, while on the second measures, it was possible in more than $70 \%$ of the ears, to adequate the measure within the prescribed. At the frequency of $1 \mathrm{kHz}$, however, half of the subjects presented differences higher than prescribed for both ears (the real value of this difference was up to $8 \mathrm{~dB}$ ). At $4 \mathrm{kHz}$ frequency, all participants presented, in both ears, differences smaller or equal to $-3 \mathrm{~dB}$ on the first phase; on the second phase, it was possible to match, in $57 \%$ of participants, the measured gain with the prescribed one for the right and the left ear in $100 \%$ of participants.

Table 2 provides results of differences in output measurement of right and left ears (frequencies from $250 \mathrm{~Hz}$ to $4 \mathrm{kHz}$ ). The percentage of differences between the value prescribed by the DSL [i/o] software and the value found on hearing aids of each ear - according to the prescription with which the child first arrive (first measure), and after hearing aid programming, the closest value possible to the prescribed one (second measure) - are shown in Table 2. It can be verified that, on the first measure, less than $45 \%$ of the ears were in accordance with the requirements, and more than $50 \%$ presented measures smaller than or equal to $-3 \mathrm{~dB}$.

Already, in the second measure, it was possible to adjust the output to the prescription in more than $70 \%$ of the ears. At the frequency of $4 \mathrm{kHz}$ however, $100 \%$ of participants, in both ears, presented values below the suggested ones on the first measure. After correction of electroacoustic characteristics (second measure), in only $29 \%$ of individuals for the right ear, and $20 \%$ of subjects for the left ear, it was possible to match the output to the prescribed measure.

Table 3 displays the overall behavior of percentage of correct responses in words, consonants, vowels and traces along the four assessments. It is observed that mean, median and maximum values tend to increase along the assessments. For vowels, the percentage of correct responses is high since the first assessment, with medians on third and fourth assessments equal to $100 \%$

The $\mathrm{p}$-values obtained in comparisons among the four assessments show that, for words, consonants and traces, there were no differences between the mean accuracy percentages on the first two assessments; only for vowel - p-value = 0,037 .

Between the second and third assessment, the p-values obtained were: words, $p=0,013$; consonants, $p=0010$; trace, $p=0020$; and vowels, $\mathrm{p}=0.00$. Between the third and fourth assessment, the $\mathrm{p}$-values were: words, $\mathrm{p}=0.08$; consonants, $\mathrm{p}$ $=0019 ;$ traces, $\mathrm{p}=0019$, and vowels, $\mathrm{p}=0.00$. These data demonstrate that there is a growing trend on the mean percentages of correct responses during the studied period. 
TABLE 1. Frequency distribution of percentages of differences between prescribed gain and gain on first and second measures after correction of electroacoustic characteristics.

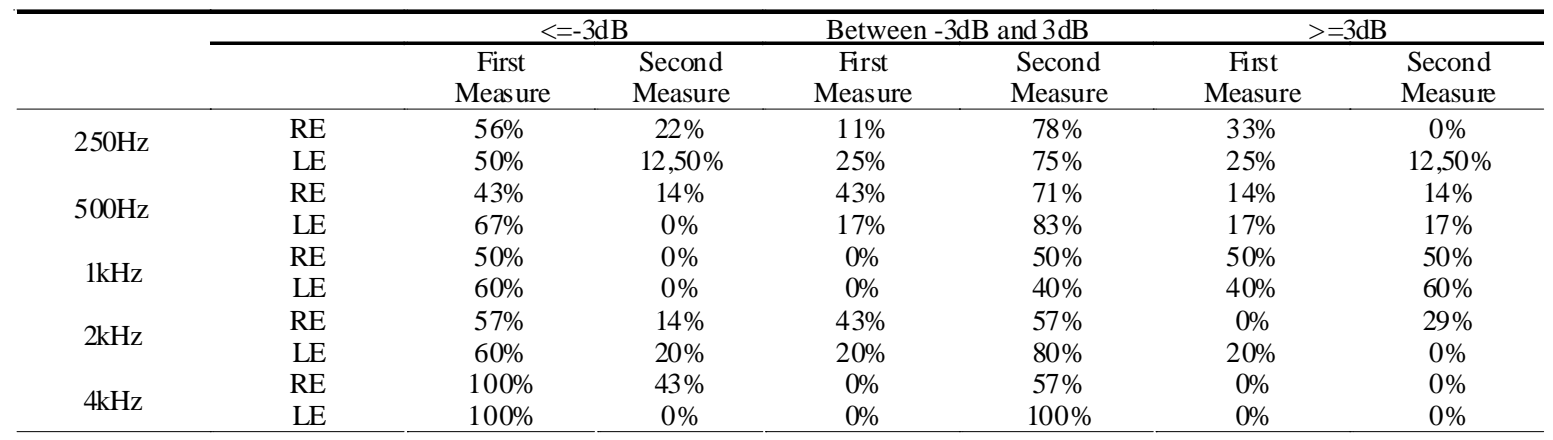

$\mathrm{RE}=$ right ear; $\mathrm{LE}=$ left ear.

TABLE 2. Frequency distribution of percentages of differences between prescribed output and output on the first and second measures after correction of electroacoustic characteristics.

\begin{tabular}{|c|c|c|c|c|c|c|c|}
\hline & & \multicolumn{2}{|c|}{$<=-3 \mathrm{~dB}$} & \multicolumn{2}{|c|}{ Between $-3 \mathrm{~dB}$ and $3 \mathrm{~dB}$} & \multicolumn{2}{|c|}{$>=3 \mathrm{~dB}$} \\
\hline & & First & Second & First & Second & First & Second \\
\hline & & Measure & Measure & Measure & Measure & Measure & Measure \\
\hline \multirow{2}{*}{$250 \mathrm{~Hz}$} & $\mathrm{RE}$ & $56 \%$ & $22 \%$ & $11 \%$ & $78 \%$ & $33 \%$ & $0 \%$ \\
\hline & $\mathrm{LE}$ & $50 \%$ & $12,50 \%$ & $25 \%$ & $75 \%$ & $25 \%$ & $12,50 \%$ \\
\hline \multirow{2}{*}{$500 \mathrm{~Hz}$} & $\mathrm{RE}$ & $43 \%$ & $14 \%$ & $43 \%$ & $71 \%$ & $14 \%$ & $14 \%$ \\
\hline & $\mathrm{LE}$ & $67 \%$ & $0 \%$ & $17 \%$ & $83 \%$ & $17 \%$ & $17 \%$ \\
\hline \multirow{2}{*}{$1 \mathrm{kHz}$} & $\mathrm{RE}$ & $50 \%$ & $0 \%$ & $0 \%$ & $50 \%$ & $50 \%$ & $50 \%$ \\
\hline & $\mathrm{LE}$ & $60 \%$ & $0 \%$ & $0 \%$ & $40 \%$ & $40 \%$ & $60 \%$ \\
\hline \multirow{2}{*}{$2 \mathrm{kHz}$} & $\mathrm{RE}$ & $57 \%$ & $14 \%$ & $43 \%$ & $57 \%$ & $0 \%$ & $29 \%$ \\
\hline & $\mathrm{LE}$ & $60 \%$ & $20 \%$ & $20 \%$ & $80 \%$ & $20 \%$ & $0 \%$ \\
\hline \multirow{2}{*}{$4 \mathrm{kHz}$} & $\mathrm{RE}$ & $100 \%$ & $71 \%$ & $0 \%$ & $29 \%$ & $0 \%$ & $0 \%$ \\
\hline & $\mathrm{LE}$ & $100 \%$ & $80 \%$ & $0 \%$ & $20 \%$ & $0 \%$ & $0 \%$ \\
\hline
\end{tabular}

$\mathrm{RE}=$ right ear; $\mathrm{LE}=$ left ear.

TABLE 3. Mean, standard deviation (SD), minimum, median and maximum of accuracy percentages in words, consonants, vowels and traces observed on the four assessments.

\begin{tabular}{|c|c|c|c|c|c|c|c|}
\hline Variable & Assessment & $\mathrm{N}$ & Mean & SD & Minimum & Median & Maxim \\
\hline \multirow[t]{4}{*}{ Words } & 1 & 10 & 16,4 & 9,0 & 0,0 & 16,0 & 28,0 \\
\hline & 2 & 10 & 21,3 & 12,8 & 0,0 & 28,0 & 36,0 \\
\hline & 3 & 10 & 42,0 & 26,7 & 0,0 & 41,7 & 76,0 \\
\hline & 4 & 10 & 52,3 & 32,1 & 0,0 & 66,7 & 84,0 \\
\hline \multirow[t]{4}{*}{ Consonants } & 1 & 10 & 46,2 & 9,5 & 34,0 & 47,9 & 58,0 \\
\hline & 2 & 10 & 49,3 & 11,4 & 34,0 & 50,9 & 62,0 \\
\hline & 3 & 10 & 58,7 & 13,2 & 35,4 & 65,2 & 70,0 \\
\hline & 4 & 10 & 68,1 & 19,5 & 35,4 & 74,0 & 88,0 \\
\hline \multirow[t]{4}{*}{ Traces } & 1 & 10 & 56,5 & 9,7 & 41,7 & 56,3 & 71,7 \\
\hline & 2 & 10 & 62,0 & 10,8 & 41,7 & 64,8 & 73,5 \\
\hline & 3 & 10 & 69,1 & 12,4 & 48,0 & 73,3 & 84,1 \\
\hline & 4 & 10 & 74,9 & 16,0 & 48,6 & 76,5 & 90,3 \\
\hline \multirow[t]{4}{*}{ Vowels } & 1 & 10 & 89,0 & 5,8 & 82,8 & 88,5 & 98,0 \\
\hline & 2 & 10 & 93,3 & 6,9 & 84,0 & 92,3 & 100,0 \\
\hline & 3 & 10 & 96,5 & 5,5 & 84,0 & 100,0 & 100,0 \\
\hline & 4 & 10 & 97,2 & 5,5 & 84,0 & 100,0 & 100,0 \\
\hline
\end{tabular}

$\mathrm{N}=$ number of participants, $\mathrm{SD}=$ standard deviation. 


\section{Discussion}

The results corroborate with studies claiming that the software DSL [i/o] is essential for the ideal protocol of hearing aid fitting in pediatric population 5,14-16. Besides being a method of prescription of hearing aid electroacoustic characteristics, this procedure considers sequential stages on the process of amplification, considering the dynamic field of hearing and the signal-noise ratio for speech amplification.

Literature suggests the use of the measure of hearing aid in coupler performance characteristics, associated to the value of the RECD, in order to predict the actual gain on the ear 3-4. The named measure derives from actual response. This method was also used in the present study - it is a rapid and less stressful procedure than the insertion gain measure, not requiring patient cooperation for any stage and can be performed in infants, children and adults, which confirm findings of other studies5, 7.

Considering the first measure obtained on performance of electroacoustic characteristics of hearing aids in coupler, it was possible to identify that the program in which children first arrived to the service - held in accordance to requirements of the software from each company and without the examination of objective measures - differed from the value prescribed by the DSL [i/o] software (see Tables 1 and 2). These results confirms a description of literature, in which the values simulated by the software did not represent the actual values, being only start points of a process and, thus, should not be used by professionals as real values 17 . This indicates that not performing the verification with objective measures underestimates the values programmed on the hearing aids because they may be different from the prescribed target values. In fact, as Marcoux and Hansen 1 stated, the verification process is crucial and it can identify the amplification that is being provided to the child - both a possible sub-amplification, which can cause damage on the amplification of the speech sounds, as super-amplification, which can cause discomfort and even increase of hearing loss.

Comparing the mean percentages of word recognition, consonants and traces on the four evaluations (Table 3), it can be observed that the accuracy percentage increased, beginning from the third assessment. One can attribute this gradual improvement in speech perception to changes on electroacoustic characteristics to the appropriate programming suggested by the DSL [i /o] 4.1 software, by emphasizing the amplification of speech sounds and improving the use of the dynamic range. It is interesting to note that this improvement in speech perception did not occur immediately, as the relationship between the first and second evaluation shows, certainly due to the necessary habituation process, which is in agreement with that described by some studies 18 19. Indeed, for consonant traces, despite the presence of auditory input, the rehabilitation is always necessary for its correct acquisition.

The familiarity of the words used in the procedures of speech perception may have also been a factor for better performance on assessments. In literature, studies demonstrate that these procedures can and should use familiar words (significant stimulus), being that the information of phoneme perception must be inferred from the response of the child 20 .

\section{Conclusion}

This study points to the necessity of verification and validation protocols as part of indication and adaptation procedures of hearing aids in children. Furthermore, the implementation of acoustic characteristics verification through objective measures is essential to provide proper amplification, being the use of the measure derived from actual response indicated.

After exchanging the hearing aid electroacoustic characteristics to the values suggested by the DSL [i/o] software, v4.1, there was an improvement in speech perception of children evaluated after the third assessment, indicating that acclimatization, familiarity with the vocabulary, and rehabilitation process should always be considered in the amplification evaluation process.

Such concerns are crucial for the auditory and language potential of each child to be achieved according to objectives of the National Hearing Health Policy. The major concern becomes, therefore, the quality of life of children with hearing loss. 


\section{References}

1. Marcoux A, Hansen M. Ensuring Accuracy of the Pediatric Hearing Aid Fitting. Trends In Amplification. 2003;7(1):1127.

2. American Academy of Audiology Pediatric Amplification Protocol. Washington 2003 [acesso em 12 fevereiro 2006]. Disponível em: http://www.audiology.org/ NR/rdonlyres/ 53D26792-E321-41AF-850F-CC253310F9DB/0/ pedamp.pdf.

3. Seewald RC, Moodie KS, Sinclair ST e Scollie SD Predictive validity of a procedure for pediatric hearing instrument fitting. Am J Audiol. December 1999;8(2):143-52.

4. Munro KJ, Hatton N. Customized acoustic transform functions and their accuracy at predicting real-ear hearing aid performance. Ear Hear. Feb 2000;21(1):59-69.

5. Seewald RC, Scollie SD. An approach for ensuring accuracy in pediatric hearing instrument fitting. Trends in Amplification. 2003;7(1):29-40.

6. Kuk KF, Ludvigsen C. Changing with the Times: ReExamining the Aided Threshold. The Hearing Review. 2003;10(Pt 3):28-33.

7. McLauchlan A. Real ear:How accurate is derived real-ear SPL when using typical clinical methodologies? In: 3rd Pediatric Conference Chicago 2004. Pôster. [acesso em 28 junho 2006]. Disponível em: http://www.phonak.com/ amy_maclauchlan_poster.pdf .

8. Ministério da Saúde. Portaria número. 2.073/GM de 28 de setembro de 2004. Insituiu a Política Nacional de Saúde Auditiva [acesso em 20 maio de 2006]. Disponível em http://dtr2001.saude.gov.br/sas/PORTARIAS/Port2004/ GM/GM-2073.htm.

9. Davis H, Silverman SR. Auditory test hearing aids. In: DAVIS H.; SILVERMAN SR. Hearing and deafness. New York: Holt Rinehart and Winston; 1970.

10. Desired Sensation Level (DSL) Method, versão 4.1. [software na internet]. Ontário: The National Centre of Audiology - The University of Western Ontário, 1996. [acesso em 12 de fevereiro de 2006]. Disponível em: http:/ /www.dslio.com/index.php?action=dload-file.
11. Moodie KS, Seewald RC e Sinclair ST. Procedure for predicting real-ear hearing aid performance in young children. American Journal of Audiology. 1994 Mar;3:2331 .

12. Koch ME. Bringing sound to life: principles and pratices of cohlear implant rehabilitation. Timorium (ML): York Press; 1999

13. Mueller HG. Probe-mic assessment of digital hearing aids? Yes, you can! The Hearing Journal. January 2001;54(1):10-7.

14. Seewald RC, Ross M, Spiro, M K Selecting amplification characteristics for young hearing-impaired children. Ear Hear. January/February 1985;6(1):48-53.

15. Cornelisse EL, Seewald RC, Jamieson DG. The input/ output formula: A theoretical approach to the fitting of personal amplification devices. The Journal of the Acoustical Society of America. March 1995;97(3):185464.

16. Scollie SD, Seewald RC, Cornelisse L, Moodie S, Bagatto M, Laurnagaray D, Beaulac S, Pumford J. The Desired Sensation Level Multistage Input/Output Algorithm. Trends Amplification. 2005; 9(4):159-97.

17. Hawkins DB, Cook JA. Hearing aid software predictive gain values: How accurate are they?.The Hearing Journal. July 2003;56(7):26-34

18. Byrne D. Implications of acclimatization for hearing aid fitting practices and research. Ear Hear. Jun 1996;17(3supl):14-25

19. Tyler RS, Summerfield AQ. Learning following cochlear implantation. Ear Hear. 1996;17(3Supl ):23-34.

20.Geers AE. Techniques for assessing auditory speech perception and lipreading enhancement in young children. Volta Review . Nov 1994;96(5):85-96. 